\title{
Water Relation Parameters of the Cortex Tissue of Fresh 'Fuji' Apple Fruit Determined by Centrifugation
}

\author{
Xue-Min Hou, Zi-Hua Wang, and Xi-Min Deng ${ }^{1}$ \\ Department of Pomology, China Agricultural University (West Campus), \\ Beijing 100193, China
}

\section{Guo-Hui Li \\ Department of Mathematics, China Agricultural University (East Campus), Beijing 100083, China}

Additional index words. Malus $\times$ domestica, apple fruit, pressure-volume curve, Höfler diagram, centrifugal force, water potential

\begin{abstract}
This experiment was carried out to obtain a pressure-volume (P-V) curve and Höfler diagram of the cortex tissue of fresh 'Fuji' apple fruit (Malus $\times$ domestica Borkh.) with a novel centrifuge method. Based on the P-V curve and Höfler diagram, several water relation parameters of cortex tissue were determined and the interrelationship of these parameters was established. Turgor loss point (TLP) occurred at $-1.74 \mathrm{MPa}$ and $\mathbf{7 3 . 7 \%}$ of relative water content $\left(R^{*}\right)$. At full hydration, osmotic potential $\left(\psi_{\mathrm{S}}\right)$ was -1.30 MPa and symplastic water accounted for $86.8 \%$ of $R^{*}$. Bulk elastic modulus decreased linearly by $28 \%$ as pressure potential declined from $1.30 \mathrm{MPa}$ at full hydration to zero at the TLP. This centrifuge technique can provide a simple and efficient way to determine water relation parameters of fleshy fruits.
\end{abstract}

The P-V curve has been used to estimate symplastic water volume, $\psi_{\mathrm{S}}$, pressure potential, turgor loss point, and elastic modulus of plant cells, tissue, and organs (Holbrook and Sinclair, 1992; Richter, 1978; Scholander et al., 1965; Tyree and Hammel, 1972). It is considered to be genetically determined (Lenz et al., 2006) and reflects drought-response properties of plant species (Dichio et al., 2003; Joly and Zaerr, 1987; Saito and Terashima, 2004). From analysis of the P-V curve, a Höfler diagram can be derived to display the components of water potential as a function of relative water content of living plant materials (Joly and Zaerr, 1987; Nobel, 2005; Richter, 1978). Traditionally, a pressure chamber has been used to obtain the P-V curve and Höfler diagram of leaves (Dichio et al., 2003; Jones and Higgs, 1979; RuízSánchez et al., 1993; Saito and Terashima, 2004) and stems (Joly and Zaerr, 1987; Tyree and Hammel, 1972). However, little information is available regarding the $\mathrm{P}-\mathrm{V}$ curve and Höfler diagram of fruit because of the difficulty in measuring fruit water relation parameters by the pressure chamber technique (Gelly et al., 2004).

Received for publication 25 Aug. 2010. Accepted for publication 20 Oct. 2010 .

We thank Hong-Na Lu, Zhi-Yi Fu, and Ke-Lin Hu for technical assistance, Wen-Suo Jia, Peter Hirst and three anonymous reviewers for valuable suggestions on the manuscript. This research was partially supported by the National Natural Science Foundation of China (No: 30771489, 30942066).

${ }^{1}$ To whom reprint requests should be addressed; e-mail dengxm@cau.edu.cn.
It is generally accepted that fruit water status is closely related to physiological processes of fruit growth and development and plays an important role in fruit quality and responses to environmental stresses (Behboudian et al., 1994; Mills et al., 1996, 1997; Mpelasoka et al., 2001; Steudle and Wieneke, 1985; Wada et al., 2008; Yamada et al., 2005). Nevertheless, monitoring fruit water status remains a challenge using a pressure chamber (Gelly et al., 2004) or pressure probe (Steudle and Wieneke, 1985). The psychrometer technique used to measure fruit water parameters is time-consuming to reach equilibrium and prone to produce errors (Behboudian et al., 1994; Gelly et al., 2004).

Rotational motion by centrifugation creates known negative tensions, which are able to pull water out of the centrifuged sample. Thus, a centrifuge method has been used to determine water retention properties of soils (Reatto et al., 2008) and xylem water potential in plants (Holbrook et al., 1995). In this study, we tried to apply a series of centrifugal force to apple cortex samples to obtain a P-V curve of cortex tissue by calculating rotation-created water potential corresponding to the measured volume of extracted water. Determining the water relation parameters of fruit by the centrifuge method may lead to further understanding of the mechanism by which fruit grow and develop in relation to water status.

\section{Materials and Methods}

Mature fresh 'Fuji' apple fruit (Malus $\times$ domestica) were purchased from a local market in Oct. 2009. The flesh of fruit remained firm, neither pithy nor floury yet. Fruit 300 to
$350 \mathrm{~g}$ in weight and 8 to $8.5 \mathrm{~cm}$ in diameter with $\approx 5 \mathrm{~mm}$ of skin removed at both calyx and stalk ends were placed in a distilled water container sealed with plastic film to ensure a relative humidity of near $100 \%$ in a refrigerator at $4{ }^{\circ} \mathrm{C}$ for $12 \mathrm{~h}$. A radial slice of cortex tissue $2 \mathrm{~cm}$ thick was taken from both sides of an apple fruit using a pair of parallel blades. A cylindrical sample, $5 \mathrm{~cm}$ in diameter and $2 \mathrm{~cm}$ in thickness, was then drawn from each piece of sliced tissue with a cutting ring. The cut surface of the samples was carefully blotted with a tissue and their initial weight (SW) measured to $0.1 \mathrm{mg}$.

A Hitachi CR21G II high-speed refrigerated centrifuge (Hitachi Koki Co., Tokyo, Japan) with a R11D2 rotor was used. Stainless steel cutting rings $(5 \mathrm{~cm}$ in diameter and $5 \mathrm{~cm}$ in height) holding the fruit samples were inserted into sample holders specially designed for this rotor. Four samples from two apples were horizontally positioned in the centrifuge rotor chamber and subjected to 13 levels of centrifugal force, ranging from 100 to $15,300 \mathrm{~g}_{\mathrm{n}}$ at $4{ }^{\circ} \mathrm{C}$.

In a preliminary experiment, the run time of rotation was determined with four samples placed in the centrifuge and subjected to a given centrifugal force. Juice extracted by centrifugation was weighed at given time intervals until its outflow nearly stopped, indicating that equilibrium had been reached between the sample water potential and the imposed centrifugal force. Further determinations were then made on the same samples by measuring the juice outflow associated with another two levels of centrifugation. We discovered that $60 \mathrm{~min}$ of constant rotation was sufficient for the samples subjected to maximum relative centrifugal force (RCF) of $1,020 \mathrm{~g}_{\mathrm{n}}, 120 \mathrm{~min}$ for $\mathrm{RCF}=10,208 \mathrm{~g}_{\mathrm{n}}$, and $180 \mathrm{~min}$ for $\mathrm{RCF}=$ $15,271 \mathrm{~g}_{\mathrm{n}}$ (Fig. 1.). Therefore, the run time of centrifugation was set as follows: $60 \mathrm{~min}$ for $\mathrm{RCF}=1,020 \mathrm{~g}_{\mathrm{n}}$ or less, $120 \mathrm{~min}$ for $\mathrm{RCF}=$ $10,208 \mathrm{~g}_{\mathrm{n}}$ or less, and $180 \mathrm{~min}$ for RCF = $15,271 \mathrm{~g}_{\mathrm{n}}$ or less.

Average distribution of centrifuge-created water potential $(\psi)$ along the fruit sample of thickness $(\mathrm{L}, \mathrm{cm})$ subjected to an angular velocity was calculated according to Reatto et al. (2008) as follows:

$$
\psi=\frac{\mathrm{k}}{6} \frac{\omega^{2} \mathrm{~L}}{\mathrm{~g}}(\mathrm{~L}-3 \mathrm{r})
$$

where $\mathrm{k}$ is a constant $\left(9.807 \mathrm{MPa} \cdot \mathrm{cm}^{-1}\right), \mathrm{g}$ is the acceleration of gravity $\left(981 \mathrm{~cm} \cdot \mathrm{s}^{-1}\right), \omega=$ angular velocity $(\mathrm{rad} / \mathrm{s})$, and $\mathrm{r}=$ radius of centrifuge rotor $(\mathrm{cm})$.

Average water potential $\left(\psi_{\mathrm{w}}\right)$ to which the apple fruit samples were subjected was computed as the mean of $\psi$ calculated from five cross-sections equally distributed along the sample thickness after each level of centrifugation. This took into consideration the nonlinear behavior of the water potential distribution along the sample thickness that was established during centrifugation, as pointed out by Reatto et al. (2008).

Juice extracted by centrifugation was collected with a reservoir cup below the base of the sample holder. Osmotic potential and soluble 
solids concentration (SSC) of apple fruit juice expressed at full hydration or extracted during centrifugation were measured with a psychrometer (Wescor Inc., Logan, UT) and a hand refractometer (Chengdu Optics Inc., Sichuan, China), respectively. After being subjected to each level of centrifugation for a predetermined time, the total volume of water extracted was measured. The centrifugation process was repeated four times and four samples were centrifuged at one time. Altogether, data of 16 samples were pooled to calculate the mean and SE for each point. The negative reciprocal of average water potential was plotted against the volume of water extracted to obtain a $\mathrm{P}-\mathrm{V}$ curve. TLP on the P-V curve was determined using the PVA method given by Schulte and Hinckley (1985).

On completion of the centrifugation process, fruit samples were dried in an oven at $85{ }^{\circ} \mathrm{C}$ for $24 \mathrm{~h}$ and their weight reached a constant level. $R^{*}$ of the apple fruit samples after each step of centrifugation was calculated using the equation as given by Kramer (1983):

$$
R^{*}=\frac{\mathrm{W}-\mathrm{DW}}{\mathrm{SW}-\mathrm{DW}} \times 100
$$

where $\mathrm{W}=$ weight measured after each centrifugation step, DW = weight of the ovendried fruit sample, and SW = weight of fruit sample at full hydration.

Average pressure potential $\left(\psi_{\mathrm{p}}\right)$ was calculated as the difference between average water potential $\left(\psi_{\mathrm{w}}\right)$ and average $\psi_{\mathrm{S}}$ derived from analysis of the P-V curve (Richter, 1978) as follows:

$$
\psi_{\mathrm{P}}=\psi_{\mathrm{W}}-\psi_{\mathrm{S}}
$$

The bulk elastic modulus $(\varepsilon)$ of apple cortex tissue was calculated according to Schulte and Hinckley (1985) as follows:

$$
\varepsilon=R^{*} \frac{\mathrm{d} \psi_{\mathrm{p}}}{\mathrm{d} R^{*}}
$$

\section{Results}

A progressive increase in the SSC of the extracted juice with maximum relative centrifugal force was detected during centrifugation (Fig. 2). This increase presumably resulted from soluble solids leakage and affected the average water potential. This effect was corrected by adding the lost $\psi_{\mathrm{S}}$ back to each data point of the water potential.

Both P-V curves of apple cortex tissue obtained before and after correction (Fig. 3) followed the typical pattern of P-V curves of other plant organs measured by the pressure chamber technique (Joly and Zaerr, 1987; Jones and Higgs, 1979; Ruíz-Sánchez et al., 1993; Tyree and Hammel, 1972). It was characterized by two parts, the nonlinear phase and the linear phase with a breakpoint between them. This inflection point represents the turgor loss point. Based on the P-V curve after correction (with solid symbols), the estimated TLP occurred at the average water potential of $-1.74 \mathrm{MPa}$ and $73.7 \%$ of relative water content. Extrapolation of the linear part of the P-V curve (dashed line in Fig. 3) intersects the y-axis at 0.7663

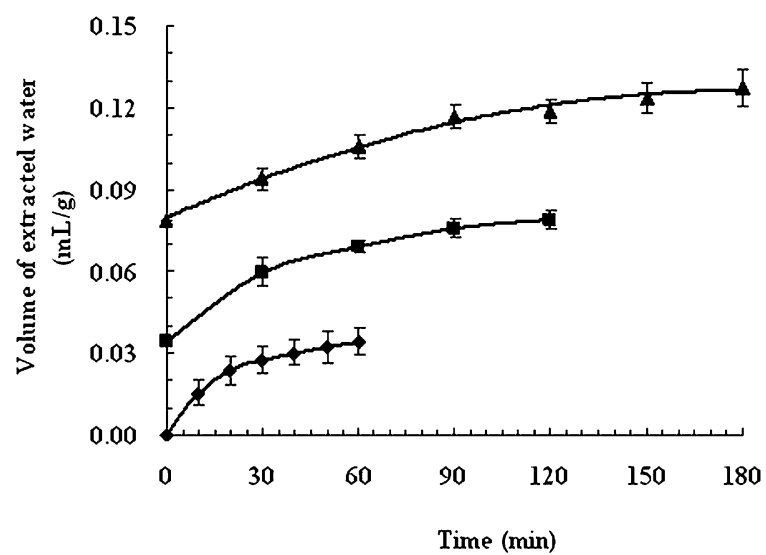

Fig. 1. Run time of centrifuge rotation versus the accumulative quantity of water extracted from apple cortex samples subjected to maximum relative centrifugal force of $1020 \mathrm{~g}_{\mathrm{n}}(\bullet), 10,208 \mathrm{~g}_{\mathrm{n}}(\mathbf{\square})$, and $15,271 \mathrm{~g}_{\mathrm{n}}(\boldsymbol{\Delta})$. Each data point represents the mean $\pm \mathrm{SE}$ of four measurements.

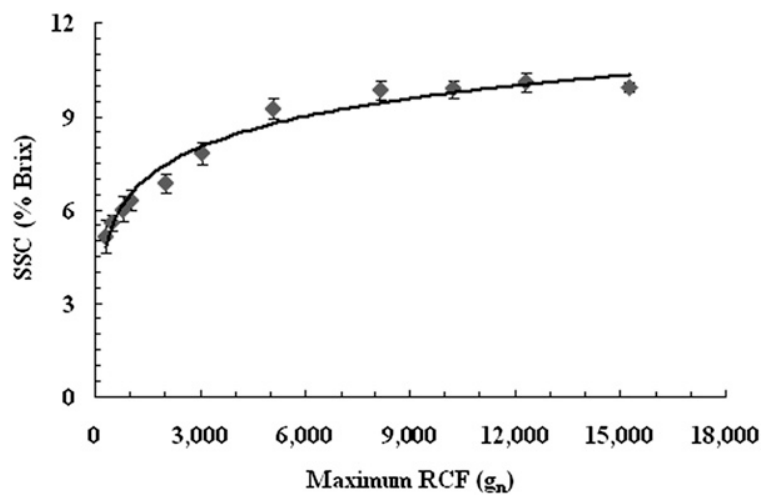

Fig. 2. Relationship of soluble solids concentration (SSC) of extracted juice with maximum relative centrifugal force $(\mathrm{RCF})$ during centrifugation of apple cortex samples $\left[\mathrm{y}=1.4166 \mathrm{Ln}(\mathrm{x})-3.3306, r^{2}=\right.$ $0.9696, P<0.001]$. Each data point represents the mean \pm SE of 16 measurements.

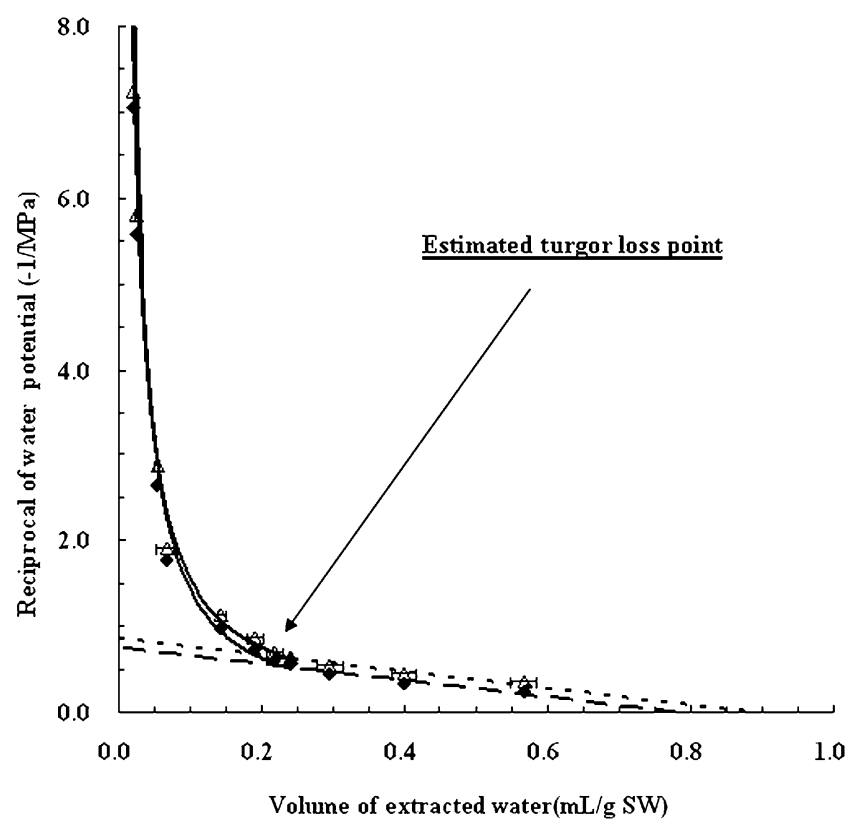

Fig. 3. Relationships between the negative reciprocal of average water potential and the volume of water extracted from apple cortex tissue before $(\triangle)$ and after $(\bullet)$ correction of water potential data. Solid lines indicate nonlinear parts of the curves in the region of positive pressure potential. The dotted line and dashed line below represent the extrapolated linear parts of the original curve $(y=-0.9691+$ $\left.0.7661, r^{2}=0.9313, P<0.001\right)$ and the corrected curve $\left(\mathrm{y}=-0.959+0.8664, r^{2}=0.9122\right)$, respectively. Each original data point $(\triangle)$ represents the mean \pm SE of 16 measurements. 
(-1/MPa), equal to an $\psi_{\mathrm{S}}$ of $-1.30 \mathrm{MPa}$ at full hydration, and intercepts the $\mathrm{x}$-axis at 0.7902 $\mathrm{mL} / \mathrm{g} \mathrm{SW}$, representing the symplastic water as $86.8 \%$ of relative water content.

The Höfler diagram (Fig. 4) obtained after the necessary correction of water potential values was consistent with the model proposed by Karl Höfler (Richter, 1978). It presented a quantitative description of the changes in $\psi_{\mathrm{p}}$, $\psi_{\mathrm{w}}$, and $\psi_{\mathrm{S}}$ in relation to the $R^{*}$ of apple fruit cortex.

The $\psi_{\mathrm{p}}$ declined from $1.30 \mathrm{MPa}$ at full hydration to zero at the TLP as the $R^{*}$ of apple fruit cortex decreased by $26 \%$. Pressure potential decreased rapidly at the beginning of the dehydration process and then slowed as it was

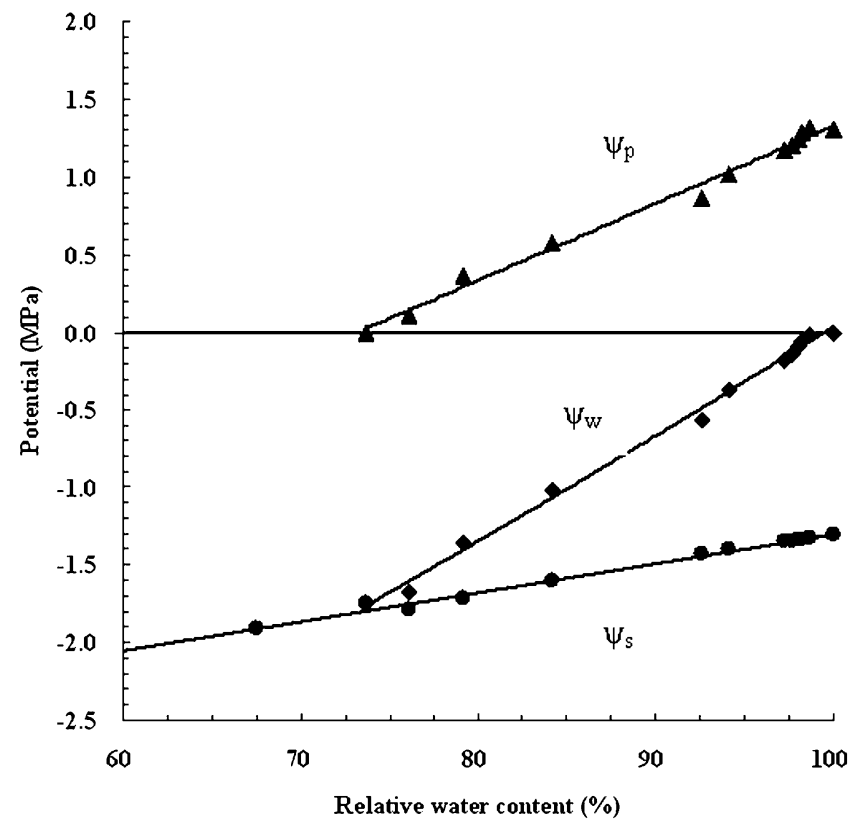

Fig. 4. A Höfler diagram derived from analysis of the pressure-volume (P-V) curve in Figure 3 showing relationships of average pressure potential $\left(\psi_{\mathrm{p}}, \boldsymbol{\Delta}\right)\left(\mathrm{y}=0.0000225 \mathrm{x}^{2}+0.0458 \mathrm{x}-3.4683, r^{2}=0.9913\right.$, $P<0.001)$, water potential $\left(\psi_{\mathrm{w}}, \bullet\right)\left(\mathrm{y}=0.000114 \mathrm{x}^{2}+0.0485-5.951, r^{2}=0.9947, P<0.001\right)$, and osmotic potential $\left(\psi_{\mathrm{S}}, \bullet\right)\left(\mathrm{y}=0.0187 \mathrm{x}-3.165, r^{2}=0.9873, P<0.001\right)$ with the relative water content of apple cortex tissue.

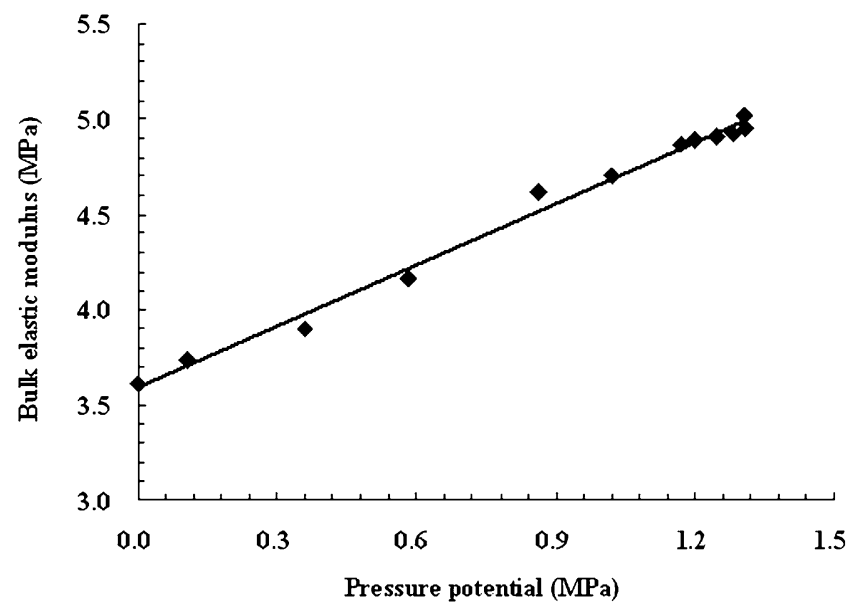

Fig. 5. Relationship between bulk elastic modulus and average pressure potential of apple cortex tissue. Bulk elastic modulus was calculated using Eq. [4] and data in Figure 4. $\left(\mathrm{y}=1.0765 \mathrm{x}+3.5872, r^{2}=\right.$ $0.9916, P<0.001)$. relationship. The average osmetic potential of fruit cortex tissue dropped by $34 \%$ from -1.30 $\mathrm{MPa}$ at full hydration to $-1.74 \mathrm{MPa}$ at the TLP.

The linear relationship between the bulk elastic modulus $(\varepsilon)$ and average pressure potential is shown in Figure 5. The value of $\varepsilon$ decreased by $28 \%$ from $5.02 \mathrm{MPa}$ to $3.61 \mathrm{MPa}$ as the pressure potential declined from 1.30 $\mathrm{MPa}$ at full hydration to zero at the TLP.

\section{Discussion}

$\mathrm{P}-\mathrm{V}$ curves have been found for vegetative tissue and organs of higher plants (Holbrook and Sinclair, 1992; Jones and Higgs, 1979; Lenz et al., 2006; Ruíz-Sánchez et al., 1993; Saito and Terashima, 2004). However, to the best of our knowledge, the present study is the first report of the P-V curve for apple fruit. The overall pattern of the fruit $\mathrm{P}-\mathrm{V}$ curve obtained by the centrifuge method was similar to those of plant leaves and stems obtained with the pressure chamber technique (Dichio et al., 2003; Holbrook and Sinclair, 1992; Lenz et al., 2006; Ruíz-Sánchez et al., 1993), displaying a nonlinear region and then a linear region after considerable water was extracted.

The increase in the SSC of extracted juice suggested that the plasma membrane of apple fruit cells was not totally impermeable to some solutes like in other cases discussed by Tyree and Hammel (1972). Yamaki and Ino (1992) reported that the concentration of total sugars in apoplastic water increased threefold and permeability to sugars across the plasma membrane rose five- to fivefold when they were compared between immature and mature apple fruit. Apoplastic solute accumulation was also observed in grape berries during growth and development (Wada et al., 2008). Thus, the high SSC in juice extracted by centrifugation might be attributed to the senescing stage of fruit used in this study. Nevertheless, the influence of soluble solid leakage on P-V curve could be eliminated if the water potential data were appropriately corrected.

From analysis of the corrected P-V curve, water energy status of fleshy fruit could be studied. The average $\psi_{\mathrm{S}}(-1.30 \mathrm{MPa})$ of apple fruit cortex at full hydration was consistent with the values of expressed apple juice measured with a psychrometer $(-1.28 \mathrm{MPa})$ or calculated $(-1.24 \mathrm{MPa})$ from the SSC $(13.7 \%$ Brix) using the van't Hoff equation (Kramer, 1983). The fruit $\psi_{\mathrm{S}}$ at full hydration was comparable with that of oak leaves (Saito and Terashima, 2004) but higher than the values reported for leaves of apple, ranging from -2.2 to $-2.5 \mathrm{MPa}$ (Jones and Higgs, 1979), almond (Ruíz-Sánchez et al., 1993), olive (Dichio et al., 2003), and other woody plant species (Lenz et al., 2006). This parameter, along with the $\psi_{\mathrm{S}}$ at the TLP, is usually used as an important criterion for determining osmotic adjustment of plant vegetative organs in response to water deficit (Dichio et al., 2003; Joly and Zaerr, 1987; Ruíz-Sánchez et al., 1993; Saito and Terashima, 2004). Osmotic adjustment of apple fruit was observed in the early growth season by measuring the fruit $\psi_{\mathrm{S}}$ with a hygrometer under different water 
conditions at predawn, midday, and dusk (Mills et al., 1997). We expect that using the centrifuge method to determine fruit water relation parameters can be of great help in studying osmotic adjustment of fruit.

The average pressure potential $(1.3 \mathrm{MPa})$ of apple fruit cortex at full hydration was similar to the maximum pressure potential (1.2 $\mathrm{MPa})$ of apple cortex cells measured with a pressure probe (Steudle and Wieneke, 1985). Much lower pressure potential of apple fruit, determined before harvest, was reported in the literature (Mills et al., 1996, 1997; Mpelasoka et al., 2001; Yamada et al., 2005). This discrepancy was probably because the fruit samples in those experiments did not reach full hydration. In addition, it could also be attributed to different apple cultivars and measuring techniques used in those studies.

The relative water content of apple cortex at the TLP was lower than the values reported for apple shoots (Diaz-Pérez et al., 1995), olive leaves (Dichio et al., 2003), and palm leaves (Holbrook and Sinclair, 1992). Richter (1978) proposed that cells with rigid walls have higher relative water content at the TLP than those with elastic walls. From an anatomical aspect, apple cortex tissue consists primarily of parenchyma cells with large vacuoles and thin cell walls except for a few vascular bundles embedded among the cortex (Esau, 1977). The low $R^{*}$ of apple cortex tissue at the TLP may result from the thin, elastic walls of apple fruit parenchyma cells.

The corrected value of $\psi_{\mathrm{S}}(-1.74 \mathrm{MPa})$ at the TLP agreed with the $\psi_{\mathrm{S}}$ value $(-1.72 \mathrm{MPa})$ calculated from the SSC of fruit samples using the van't Hoff relation. Lower $\psi_{\mathrm{S}}$ (more negative values) was reported for 'Fuji' apple fruit before harvest (Yamada et al., 2005). However, the reported $\psi_{\mathrm{S}}$ may have been overestimated because it suggested that the SSC of these fruit was higher than the value measured. The $\psi_{\mathrm{S}}$ of apple shoots at the TLP estimated by Diaz-Pérez et al. (1995) was higher than the $\psi_{\mathrm{S}}$ of apple fruit cortex at the TLP we obtained. Low $\psi_{\mathrm{S}}$ of apple cortex at the TLP implies a high concentration of solutes in cells, which may enable the fruit to attract more water and maintain pressure potential during periods of water deficit.

It should be pointed out here that this experiment was conducted throughout at $4{ }^{\circ} \mathrm{C}$. This low temperature could lead to a relatively higher $\psi_{\mathrm{S}}$ (less negative) because $\psi_{\mathrm{S}}$ is reversely related to temperature according to the van't Hoff relation. If temperature rose, $\psi_{\mathrm{S}}$ would become slightly more negative, assuming that air pressure was kept constant.

The symplastic water volume represents the sum of water in vacuoles and cytoplasm (Kramer, 1983). The symplastic water in apple cortex was $86.85 \%$ of $R^{*}$, higher than that reported in olive leaves (Dichio et al., 2003). A high quantity of symplastic water is probably the result of the thin cell walls and large vacuoles of parenchyma tissue of apple fruit (Esau, 1977). This property may allow the apple fruit to delay the occurrence of the TLP until more negative water potential occurred as pointed out by Dichio et al. (2003). In addition, compared with a large amount of symplastic water, matric water in apple fruit was presumably negligible and matric potential was ignored in this study.

A much higher specific capacitance of apple fruit compared with that of apple leaves (Jones and Higgs, 1979) implies that attached fruit may also act as a water storage organ and play an important role in keeping the daily water balance of the tree-like stem of palm reported by Holbrook and Sinclair (1992). This point was supported by the observation of reversal water flow out of attached apple fruit to other parts of tree (Lang, 1990; Tromp, 1984). Our results suggested that if fruit water potential dropped by 1.0 $\mathrm{MPa}$, an apple of $250 \mathrm{~g}$ could provide $34 \mathrm{~g}$ of water for $28 \mathrm{~min}$ of leaf transpiration at a rate of $20 \mathrm{mg} \cdot \mathrm{m}^{-2} \cdot \mathrm{s}^{-1}$.

The bulk elastic modulus of apple cortex tissue was comparable with the values of olive leaves estimated by the pressure chamber technique (Dichio et al., 2003). Dependence of the bulk elastic modulus on pressure potential was also observed in apple fruit cells (Steudle and Wieneke, 1985) and olive leaves (Dichio et al., 2003). Steudle and Wieneke (1985) reported that the elastic modulus of apple fruit cells was a function of cell size and larger cells showed a higher elastic modulus. Variation in $\epsilon$ values could be the result of the difference in cellular characteristics between plant materials (Steudle and Wieneke, 1985) and the experimental methods used as well (Schulte and Hinckley, 1985).

It is well known that elastic modulus is closely related to the rigidity of plant cell walls (Nobel, 2005). Plant cells with rigid walls have a higher elastic modulus than those with elastic walls (Kramer, 1983). A lower elastic modulus of apple probably means higher elasticity of the fruit. An increase in apple tissue elastic modulus at high pressure potential may contribute to the firmness of apple fruit flesh before any water loss during storage.

Psychrometer has been previously used to measure water and $\psi_{\mathrm{S}}$ and to determine pressure potential of pear (Behboudian et al., 1994) and apple (Mills et al., 1996; Mpelasoka et al., 2001; Yamada et al., 2005) fruits. However, this traditional method can only at a given time provide limited snapshot measurements to study growth and development of fruit related to water status. The Höfler diagram, derived from analysis of the P-V curve, presents the components of fruit water potential in relation to $R^{*}$. Therefore, dynamic changes in water energy status of attached fruit may be able to be determined in situ by continuously monitoring fruit water content.

In summary, the centrifuge method used here to obtain the P-V curve of apple fruit may be used to determine fruit water status at different developmental stages and under various environmental conditions. This highly efficient and less time-consuming technique allows one to further study the roles that water plays in the growth and development of apple and other fruits in laboratories.

\section{Literature Cited}

Behboudian, M.H., G.S. Lawes, and K.M. Griffiths. 1994. The influence of water deficit on water relations, photosynthesis and fruit growth in Asian pear (Pyrus serotina, Rehd.). Sci. Hort. 60:89-99.

Diaz-Pérez, J.C., K.A. Shackel, and E.G. Sutter 1995. Relative water content and water potential of tissue-cultured apple shoots under water deficits. J. Expt. Bot. 46:111-118.

Dichio, B., C. Xiloyannis, K. Angelopoulos, V. Nuzzo, S.A. Bufo, and G. Celano. 2003. Drought induced variations of water relations parameters in Olea europaea. Plant Soil 257:381-389.

Esau, K. 1977. Anatomy of seed plants. 2nd Ed. John Wiley \& Sons. New York, NY. p. 445-448.

Gelly, M., J. Marsal, M. Mata, A. Arbones, J. Rufat, and J. Girona. 2004. Fruit water potential: A comparative study with other water potential parameters. Acta Hort. 646:35-40.

Holbrook, N.M., M.J. Burns, and C.B. Field. 1995 Negative xylem pressures in plants: A test of the balancing pressure technique. Science 270: 1193-1194.

Holbrook, N.M. and T.R. Sinclair. 1992. Water balance in the arborescent palm, Sabal palmetto. I. Stem structure, tissue water release properties and leaf epidermal conductance. Plant Cell Environ. 15:393-399.

Joly, R.J. and J.B. Zaerr. 1987. Alteration of cellwall water content and elasticity in Douglas-fir during periods of water deficit. Plant Physiol. 83:418-422

Jones, H.G. and K.H. Higgs. 1979. Water potential-water content, relationships in apple leaves. J. Expt. Bot. 30:965-970.

Kramer, P.J. 1983. Water relations of plants. Academic Press, San Diego, CA. p. 24-56.

Lang, A. 1990. Xylem, phloem and transpiration flows in developing apple fruits. J. Expt. Bot. 41:645-651.

Lenz, T.I., I.J. Wright, and M. Westoby. 2006. Interrelations among pressure-volume curve traits across species and water availability gradients. Physiol. Plant. 127:423-433.

Mills, T.M., M.H. Behboudian, and B.E. Clothier. 1996. Water relations, growth, and the composition of 'Braeburn' apple fruit under deficit irrigation. J. Amer. Soc. Hort. Sci. 121:286-291.

Mills, T.M.M., H. Behboudian, and B.E. Clothier. 1997. The diurnal and seasonal water relations, and composition, of 'Braeburn' apple fruit under reduced plant water status. Plant Sci. 126:145-154.

Mpelasoka, B.S., M.H. Behboudian, and T.M. Mills. 2001. Water relations, photosynthesis, growth, yield and fruit size of 'Braeburn' apple: Responses to deficit irrigation and to crop load. J. Hortic. Sci. Biotechnol. 76:150 156.

Nobel, P.S. 2005. Physicochemical and environmental plant physiology. 3rd Ed. Elsevier Academic Press, Burlington, MA. p. 39-82.

Reatto, A., E.M. da Silva, A. Bruand, E.S. Martins, and J.E.F.W. Lima. 2008. Validity of the centrifuge method for determining the water retention properties of tropical soils. Soil Sci. Soc. Amer. J. 72:1547-1553.

Richter, H. 1978. A diagram for the description of water relations in plant cells and organs. J. Expt. Bot. 29:1197-1203.

Ruíz-Sánchez, M.C., M.J. Sanchez-Blanco, J. Planes, J.J. Alarcon, and A. Torrecillas. 1993. Seasonal changes in leaf water potential components in two almond cultivars. J. Agric. Sci. 120:347-351

Saito, T. and I. Terashima. 2004. Reversible decreases in the bulk elastic modulus of mature 
leaves of deciduous Quercus species subjected to two drought treatments. Plant Cell Environ. 27:863-875.

Scholander, P.F., H.T. Hammel, E.D. Bradstreet, and E.A. Hemmingsen. 1965. Sap pressure in vascular plants. Science 148:339-346.

Schulte, P.J. and T.M. Hinckley. 1985. A comparison of pressure-volume curve data analysis techniques. J. Expt. Bot. 36:1590-1602.

Steudle, E. and J. Wieneke. 1985. Changes in water relations and elastic properties of apple fruit cells during growth and development. J. Amer. Soc. Hort. Sci. 110:824-829.

Tromp, J. 1984. Diurnal fruit shrinkage in apple as affected by leaf water potential and vapour pressure deficit of the air. Sci. Hort. 22:81-87.

Tyree, M.T. and H.T. Hammel. 1972. The measurement of the turgor pressure and the water relations of plants by the pressure-bomb technique. J. Expt. Bot. 23:267-282.

Wada, H., K.A. Shackel, and M.A. Matthews. 2008. Fruit ripening in Vitis vinifera: Apo- plastic solute accumulation accounts for preveraison turgor loss in berries. Planta 227: 1351-1361.

Yamada, H., T. Morita, and S. Amano. 2005. Water relations in fruit, leaves and stems of two apple cultivars that differ in susceptibility to watercore. J. Hort. Sci. Biotechnol. 80:70-74.

Yamaki, S. and M. Ino. 1992. Alteration of cellular compartmentation and membrane ermeability to sugars in immature and mature apple fruit. J. Amer. Soc. Hort. Sci. 117:951-954. 